\title{
The Development Present and Trend of Intelligent Munitions
}

\author{
Pan Xiao ${ }^{1}$ \& Guanglin $\mathrm{He}^{1}$ \& Jiemin $\mathrm{Li}^{1}$, Junhu $\mathrm{Li}^{2}$ \& Gang Zhang ${ }^{2}$ \\ ${ }^{1}$ Beijing Institute of Technology - School of Mechatronic Engineering, Beijing, 100081, China \\ 2JunhHuaihai Industry Group Co. LTD, 046012, Changzhi, Shanxi, 046012, China
}

Keywords: Intelligent munitions; Cruise flight ammunition; self-destruction; Network cooperative engagement.

\begin{abstract}
The improvement of modern science and technology, changes in the form of war, have prompted the development of intelligent munitions. This paper first introduces the concept of intelligent ammunition and classification, then the use and technical parameters of several foreign advanced munitions are summarized. Finally, the paper pointed out the development trend of intelligent ammunition: Emphasize "self-destruction" function; Diversity development of multipurpose cruise flying bullets; Network cooperative engagement.
\end{abstract}

\section{The background of intelligent munition}

With the rapid development of modern science and technology, the competition between countries has towards to the high technology. The Vietnam war, the United States used laser guidance and TV guided bombs, made 10 times higher effect than no guided bomb combat; The gulf war, various high-tech weapons were mostly used and have played a great power.

As far as the ammunition technology is concerned, with the developments of the modern warfare and computer technology, large scale integrated circuit technology, light electrical technology, how to improve the efficiency of the role of ammunition to the target, accuracy, military reconnaissance, battlefield surveillance become the key of the research, which prompted the ammunition technology from the traditional way towards to informationization and intelligent. In the war of Kosovo, Iraq and Libya, intensive "hail" bombarded scene have not been seen, instead, they used the air superiority to achieve the precision. The United States and its Allies can accurately follow their inclinationsly to destroy any goal in which they were interested. Therefore, many people are surprised at the short time of the war. Thus, the wide application of intelligent ammunition is not only an important sign of the changes of modern war, but also one of the key factors for final decision. From those local wars, we know that we must speed up the development of the intelligent ammunition in order to adapt to the needs of the possibility of future war.

\section{The overview of intelligent munition}

\subsection{Definition and classification of intelligent munition}

Intelligent ammunition is an ammunition which can automatically search, identify and attack targets without the help of outside devices (such as a laser designator).It uses the artificial intelligence technology, sound waves, radio waves, visible light and laser to choose the target and the means of attack. Intelligent ammunition can be divided into two categories: one is precision-guided munitions. Another is ammunitions which use sensors to detonate. A prominent feature of the intelligent ammunition is that it can obtain and make use of effective information to modify the ballistic and hit the target. Therefore it is an ammunition with high combat effectiveness. [6]

\subsection{Typical example abroad}

Microminiature gliding guided ammunition-“Scorpion”. "Scorpion" is a lightweight, compact type unpowered gliding guided ammunition, which was developed by The Lockheed Martin Company of The United States. It can adapt to a variety of launch system and deal with the large 
range of targets in a low cost, such as: building, staff, light armored vehicles, trucks, cars, missile launchers and artillery or artillery positions.

The tactical and technical index of "Scorpion":

Length: 546.1mm; Weight: less than 15.88 KG; Diameter: 108mm; Maximum range: more than $18.52 \mathrm{~km}$.

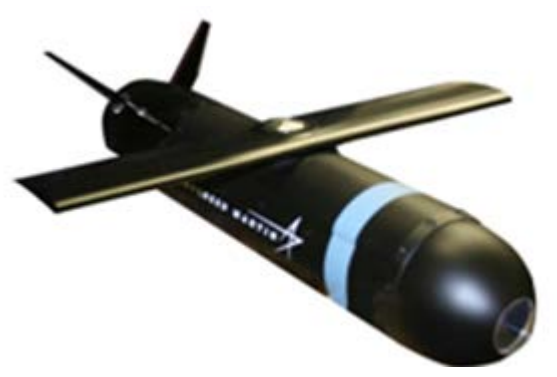

Figure 1. “Scorpion”

The ammunition adopts the modular design. It consists of seeker, wing, the warheads, guided tank and control tank. Initially, it is equipped with the semi-active laser seeker. Then, through transforming it can also be equipped with Infrared imaging seeker, short-wave infrared seeker or millimeter wave seeker, which can make sure that the precision of the ammunition is less than $1 \mathrm{~m}$ and the collateral damage is significantly reduced. Its warhead also uses modular design, which can elect appropriate warhead according to different combat missions.

Multiuse intelligent ammunition in Italy-MIMS

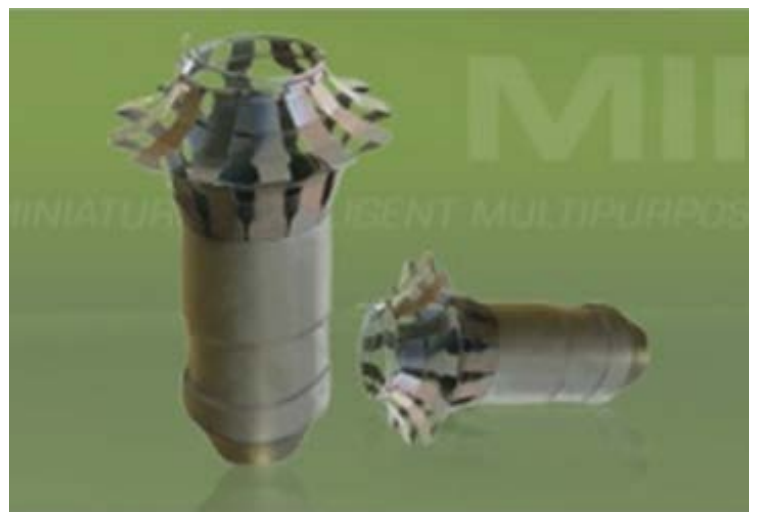

Figure 2. MIMS

For the convenience of fighting in built-up areas, the Israel Military Industries (IMI) develops the MIMS to improve the efficiency of operations, to differentiate civilian and military targets and to reduce collateral damage. The main characteristics of MIMS are: a dual-function model warhead, attack different goals adaptively, adapt to the different delivery platform, the function of activation and failure, the ability to survive, the low cost. MIMS can be launched by rocket and dispensers. It can travel to and attack the goal resulting from its propulsion system and a variety of sensors. MIMS is Equipped with program before launching and it can only attack goals that has been selected. It can attack the weak parts of the goal and can greatly reduce the collateral damage." Hatchet”

" Hatchet" is an aircraft based and gliding intelligent ammunition, it is mainly used to attack the terrorists and the missile launcher. "Hatchet" is developed by the ATK company in the USA, it can be released by the F-35 fighter and Small unmanned aerial vehicle. Its 3 end rudders and 3 folding wings will unfold after launching, flying to the target glidingly.

Precision autonomous ammunition - "Net-spear"

" Net-spear" is developed by the USA, it has the ability of precise strikes. It can be used to attack the air defense system and multiple small moving targets. The ammunition is mainly composed of photoelectric seeker, range finder, servo control part, fuze and warhead, computer, GPS/network 
communication module, battery and other parts. The tactical and technical index: Diameter: $\phi 70 \mathrm{~mm}$; Length: 432mm; Weight: 3.6kg; Motor Overload: 1.5g.

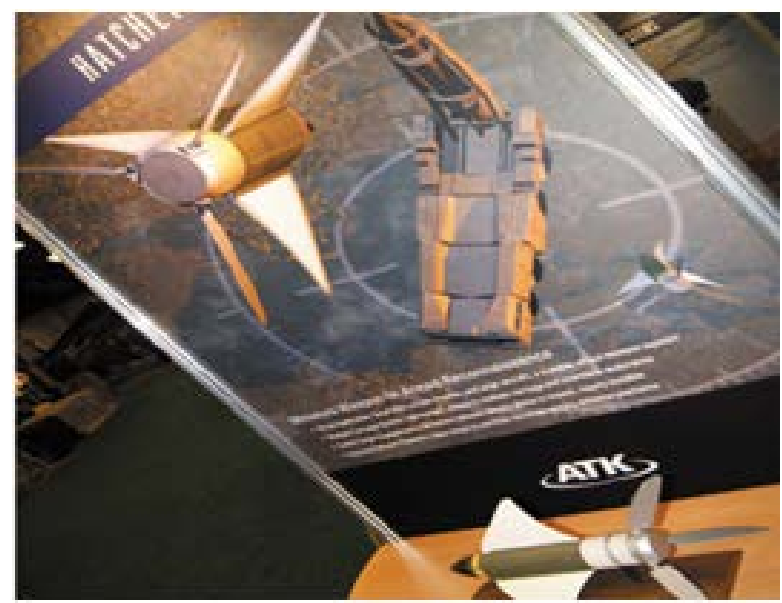

Figure 3. "Hatchet"

BAT and its second generation. BAT attacks the top armor of the target with tandem and hollow warhead. It can destroy various kinds of tanks which have explosive armours. The second generation uses the millimeter wave radar/infrared imaging seeker instead of the original double color infrared seeker in order to improve the performance under the condition of bad weather and interference.

Loitering Unit

At present, the most famous loitering units are "LOCAAS" and "LOCPAD". "LOCAAS" uses a low-cost laser radar seeker, multimodal warhead. It can search, identify, and destroy a large number of maneuvering targets on the ground, and can also attack the air defense weapon and threatening missile system. It can be launched by tactical missiles, multiple rocket launchers and also the plane in the air.

"LOCPAD" is integrate weapons systems of intelligence, surveillance and reconnaissance (ISR) of the U.S. air force. It is used to deal with the preferential target and limit the target in a particular area for a long time. The ammunitions combat with the target in a cooperative way. The coverage of "LOCPAD" is decided by its flying speed, altitude and relative velocity. The attrition rate is calculated by the accurate data.

\section{Development tendency of the intelligent ammunition}

\subsection{Emphasizing the function of "self-destruction, self-failure and self-disability"}

In the gulf war, wars in Afghanistan and Iraq, and The fact that U.S. military left at least 170000 misfire bullets in the desert storm, resulting in a large number of civilian casualties strongly condemned by the international community. Therefore, the ammunition areas need urgently to solve the problem in the future. To solve this problem, we must Emphasize the function of "self-destruction, self-failure and self-disability" of intelligent ammunition. The main technologic methods include: To develop a new fuze, to develop the fuze which is existed and to increase the self-destruct mechanism. To develop a new fuze, it will result in a high cost and a long development period; it is hard to develop the fuze which is existed. By contrast, to increase the self-destruct mechanism is feasible for its low cost and short development period.

At present, Using the electricity can meet the requirements of "self-destruction, self-failure and self-disability" of intelligent ammunition. But the cost is much high. So it is now a problem how to improve the reliability of product, the miniaturization of the power supply and long-term storage. [10, 11]

\subsection{Diversification of the cruise munition}

Compared with other intelligent ammunition, the cruise ammunition has two characteristics. First, it has strong penetration ability. Using the trajectory flight or high-speed flight of the "mother 
ammunition”, cruise ammunition can quickly enter the target zone. The probability being intercepted and destroyed is much low than unmanned aerial vehicle (uav) system. Then, the time it can stagnate in the air is long, so it can be used to perform tasks such as reconnaissance and damage effect evaluation.

Concerning the difference of combat mission and battlefield environment the cruise ammunition will be perfected as following aspects:

The diversification of the platform. The delivery way of the future cruise ammunition should have strong versatility.

The integration of investigation, blow and evaluation. Future cruise ammunition should also have the ability to target for precision, in order to improve operational efficiency and save operational resource besides the ability of investigation and blow.

The time it can stagnate in the air must be longer so that it can realize the maximization of the combat effectiveness.

The communication technology must be more perfect. Future cruise ammunition should be towards to the diversity of data communication, data transmission, anti-interference and broadband communications.

The sensors in the ammunition must be more advanced, and the ammunition should be invisible.[1]

\subsection{Network-coordinated of the intelligent munition}

In the modern war, a new target has been appeared- time critical target (TCT).It is a target that its weaknesses and the timing of the blow are limited by the limited time window, and we must find, locate, and identify the target in the limited "attack window" or "opportunity". According to the American KongLiuHai applications center (with ALSA), time critical target is a Short time target that is identified by the JFC as one which we need response immediately.[ 7 [ [9]

The typical examples of TCT are Air defense missile system and radar station which operates intermittently. TCT is hard to track, locate and blow.[2]

We can use the Networked intelligent ammunitions to damage TCT in a coordinated way. The Networked intelligent ammunitions are ammunitions which can communicate with each other and can also realize information exchange on the battlefield. Network-coordinated of the intelligent ammunition have its advantage of realizing a high hit accuracy as well as expanding the range.[3]

Network-coordinated of the intelligent ammunition is based onC4KSIR network operational system. On its function aspect, it is mainly composed of network communications, situational awareness, cooperative control, task allocation; for the physical structure, it is mainly composed of control system and measurement and control command system in order to communicate with each other. Networked collaborative combat technology involves high dynamic ad-hoc network communication technology, collaborative perception multi-source data fusion technology, swarm intelligence decision-making and coordinated control key technology.[8]

At present, with the development of the scope and characteristics of TCT, The task of Network-coordinated of the intelligent ammunition to blow TCT is also improved. The development trend can be summarized as following: The task planning will be more intelligent, the operational decisions will be made more independently, and the process will be more quickly. And operations area will be more three-dimensional.

\section{Conclusion}

This paper mainly introduces the development definition and types of intelligent ammunition, lists some foreign advanced intelligent ammunitions, introduces their use and main technical indicators. IN the end, the paper summarizes the trend of future development of intelligent ammunition combining with its current situation: with the development of communication technology, the network-coordinated of the intelligent ammunition will become the main trend.

\section{Reference}


[1] CHENG feng \& WANG hua. 2011. The latest development overview and outlook of the loitering unit [A]. SILICON VALLEY.

[2] LIAO yanping \& LIU li. 2009. The development trend of ammunition forregional control [A]. Maneuverable Missile.

[3] LI wei \& ZHANG wei. 2009. Mission planning of networking intelligent ammunition [A]. Journal of system simulation.

[4] M234 M235 SELF-DESTRUCT FUZES.L3 communications [C]//communications.39Th Annual Gun \& Ammunition Missiles \& Rocket conference, USA: [s.n.].2004

[5] The new favorite of weaponry- intelligent ammunition.

[6] WANG pin \& LUO feng. The use of intelligent ammunition in the network centric warfare. Wireless technology

[7] WANG jiabo \& LIU li. 2012. Coordinated combat of intelligent ammunition for time critical target [A]. Journal of Arrows and guidance.

[8] WANG haoyu \& XU xueqiang. 2010. Network-coordinated technology of the intelligent ammunition [A].Act Armamentarii [A].

[9] Wilson G.2002. A time-critical targeting roadmap [D]. Alabama: Air University.

[10]ZHAO Yuqing. 2009. The convention cluster munitions and bomblet fuze development trend [J].Journal of Detection \& Control.

[11]ZHAO Yuqing. 2013. The development status and trend [A]. Journal of detection and control. 